\title{
Leading trends in the development of contemporary pedagogical education
}

\author{
Olga Morozova ${ }^{1, *}$ \\ ${ }^{1}$ Altai State University, Institute of Pedagogical Education, 656015, 44 Molodezhnaya str., ap.51, \\ Barnaul, Russia
}

\begin{abstract}
The article reveals the leading trends in the development of pedagogical education as the key problem of its renewal in modern conditions. The main objective of the study is to review scientific and theoretical foundations of these trends. The practical value of the results obtained is indicated as the main guidelines for the modernization of the substantive aspects of modern pedagogical education, taking into account the identified trends in their design.
\end{abstract}

\section{Introduction}

Modernization processes that encompass all spheres of life in Russian society have a serious impact on the development of modern pedagogical education, imposing fundamentally new requirements on the quality of its content, while maintaining the continued relevance of finding the answer to the following question: what should future teachers teach today? It is clear that this search is associated with identifying the leading trends in the development of the content of teacher education, which is to be the main determinants of its further modernization.

The problem of updating the content of pedagogical education is currently the subject of mny researches, such as V. A. Adolf, A. V. Antyukhova, V. P. Bespalko, V. A. Bolotov, E. V. Bondarevskaya, G. A. Bordovsky, V. A Kozyreva, S. V. Kulnevich, O. P. Morozova, N. F. Radionova, Yu. V. Senko, V. V. Serikova, A. P. Tryapitsyna, et al. Analysis of the scientific publications of these and other scientists speaks in favour of the fact that a certain fund of scientific research has been accumulated in pedagogical science by today, in which certain features are devoted to the development of modern pedagogical of education. At the same time, in the context of the problem we discuss in the paper, the results of these studies are mosaic and fragmented and do not represent a holistic "picture" revealing the systemic vision of the changes taking place in the content of modern pedagogical education and forming a "tendency approach" to the teaching staff in terms of its selection and structuring.

In this regard, the purpose of our study was to identify the leading trends in the development of the content of modern pedagogical education as a system of holistic ideas about the changes taking place in it and taking them into account in its further development.

\footnotetext{
* Corresponding author: kpvshiot@mc.asu.ru
} 


\section{Research objectives}

- Determine the role of the processes of modernization in society and education in updating the content of teacher education;

- Identify trends in the development of the content of modern pedagogical education and reveal their components;

- Justify the need to take into account these trends in the content of teacher education.

\section{Research methods}

- Analysis of scientific and pedagogical literature on the research problem;

- Content analysis of textbooks and teaching aids on pedagogical disciplines.

\section{Results}

The large-scale planetary changes taking place in the world demanded strengthening the role of the human factor, the need to affirm the human, which led to a paradigm shift of traditions in general and in pedagogical education. As a result, the humanitarian paradigm has replaced the technocratic paradigm. Researchers view the humanization of education as "the formation in humans of special, proper humen with an attitude to the world and to themselves, theor own activity in it" [1, p.23].

In this context, it is possible to identify the tendency in the content of modern pedagogical education of its humanization, which finds itself in the following:

- The content of pedagogical education is considered not only as a social socio-historical experience accumulated in scientific texts, curricula and textbooks, but also as an experience brought into the pedagogical process by its participants (teachers and students), as well as the experience that is born in the pedagogical process itself, "here and now". At the same time, "the content of education (part of social experience, isomorphic to it) unfolds in the context that constitutes the cultures of the subjects of vocational training. Here, specific relationships are realized between the teacher and the student, which make each of them a part of understanding, and the understanding itself is co-creation. In this situation, mutual understanding becomes the "semantic content of being," a way of living together" and experiencing learning by both the teacher and the student" [2, p. 153];

- Openness of the content of pedagogical education, which exposes itself primarily in the open position of its participants. Thus, the teacher not only acts as the "plenipotentiary" of pedagogical science, while setting forth the official point of view adopted in science. He is an author, presenting to students his own position, expressing his personal attitude to knowledge. On the other hand, the students themselves formulate and express their opinions on certain issues in the content of teacher education. The personal orientation of the latter is characterized by the fact that elements of the pre-university school experience of future teachers and the results of their daily self-education activities are actively included in its structure;

- Dialogization of the content of teacher education. This is primarily about the dialogization of educational texts, involving a fundamentally different language for the presentation of educational material, when the author conducts a conversation, a dialogue with the learner. The text itself is accompanied by various kinds of problematic issues, reasoning. A number of questions are rhetorical, others are open, i.e. questions that are currently not answered in pedagogical science. Their purpose is to stimulate the mental activity of students, to develop prognostic abilities, the ability to put forward their own hypotheses, etc. 
Integrative processes are an objective necessity and an identification mark of the development of modern society. There is no doubt about the statement of the German philosopher M. Buber, "We live in a stream of inclusive reciprocity." [4, p. 37]

Today, the trend of integrating the content of pedagogical education is becoming more and more obvious:

- Integration of pedagogical knowledge and knowledge of other sciences (psychology, ethics, aesthetics, valeology, etc.). "This knowledge undergoes a certain transformation as soon as they begin to be used in the context of pedagogical problems, they acquire a certain pedagogical orientation, reorganizing in accordance with the specifics of the problems being solved. This knowledge is not applied directly, but through pedagogical ideas and concepts that, as it were, absorb knowledge gained in related sciences and synthesize them into a new, proper pedagogical system" [5, p. 48]. As a result of this integration of interdisciplinary knowledge, future teachers form holistic ideas about professional activity, a systemic vision of the pedagogical reality;

- Integration of scientific pedagogical knowledge and non-scientific knowledge. Today, science recognizes extra-scientific sources of comprehension of reality. As such sources are art and fiction, folk traditions, mythology, etc. So, for example, a lively artistic language, unlike strict scientific, is characterized by emotion, figurativeness, brightness, versatility. The authors of works of art holistically reveal the personalities of their heroes, thereby ensuring the deep penetration of students into their feelings, experiences, and contact with the fate of another person. The inclusion of fragments of works of art, films about school, a teacher in the content of pedagogical education, etc., when being merged with scientific knowledge, it creates conditions for future teachers to form a systematic view of various pedagogical phenomena, comprehend the semantic context of scientific and pedagogical knowledge, strengthen educational and professional motivation.

Russia's accession to the innovation path of development required representatives of any professional sphere of high mobility, the ability to quickly adapt in an ever-changing world, in conditions of increasing uncertainty, to be the subject of their own life activity. Such high requirements were reflected in the new strategy for the development of education based on the competence approach, which determined the competence-oriented focus of the content of teacher education as one of the leading trends in its development. In this case, among the components of the content of education, along with knowledge, skills and abilities, experience in solving problematic, non-standard practical tasks are of particular importance. That is, the existing problematization of the content of pedagogical education, or (in another terminology) the task-oriented structuring of educational material, appeals to a fundamentally different system of tasks, which is to be a competence-based one, ensuring the practice-oriented nature of the content of education. The similar nature of the content of pedagogical education is also provided by the inclusion in its structure of real practical (production) experience of employers (their representatives), which is used for various didactic purposes, to "illustrate or confirm scientific regularities; specification of theoretical positions; strengthening the depth of theoretical knowledge; giving more convincing scientific and theoretical knowledge; ensuring the integrity of the perception of the studied processes and phenomena; the formation of students' motivation of professional activity, etc." [6, p. 91].

The processes of globalization that have embraced the world at present are in close dialectical connection with another group of processes - regionalization. Analysis of the scientific literature (L. A. Artemyeva, Yu. G. Kruglov, I. G. Metalova, N. I. Nikitina, N. K. Sergeev, and others) allowed us to identify the corresponding trend in the development of the content of pedagogical education - its regionalization, which implies taking into account the peculiarities of the region, its traditions. With regard to pedagogy, this means the inclusion a system of ideas about the activities of various types of innovative 
educational institutions operating in the region into the structure of the content of pedagogical education, as well as teacher skills related to work in specialized classes, knowledge of the specifics of small rural schools, pedagogical features of work with a small group of students and with different age groups of students.

Elements of folk pedagogy reflecting the genesis of the regional education system are also included in the structure of the content of modern pedagogical education. They greatly enrich scientific pedagogical knowledge, arming the future teacher with new approaches to educating and teaching a child based on a synthesis of scientific and theoretical knowledge and popular pedagogical regional traditions. In general, the regional component "permeates" the entire content of pedagogical education, because each topic is somehow refracted through the "prism" of the regional context.

One of the powerful factors for the development of the economy and the whole way of life of a person is modern information technologies, which cause qualitative changes in the format of higher pedagogical education and its content, and, accordingly, the ability to fix another trend in the development of this content - informatization (more can be found in research conducted by A. A. Veriaev, A. N. Dakhin, E. K. Samerkhanova, V. A. Starodubtsev, A. A. Ushakov, etc.). Within the framework of this trend, it became possible, through the content of pedagogical education, to have "fundamentally new for pedagogy forms of implementing the principle of visibility, allowing to visualize (make visible) the quantitative and qualitative characteristics of such properties of objects that are not directly perceptible. For example, complex characteristics of human states, positions (health, skill, training, etc.)" [7, p. 188]. The content of pedagogical education is fundamentally reorganized under the influence of the use of technologies of augmented and virtual reality, when training is carried out in an environment as close as possible to reality, or in conditions that are still impossible to create in pedagogical reality today. In this case, the theory comes as close as possible to practice, knowledge acquires a deeply personal character, the processes of acquiring skills and skills are dynamized to the maximum extent, motivational activity increases, and the predictability of professional thinking develops.

\section{Conclusion}

The results of our research indicate that all the identified trends in the development of the content of modern pedagogical education are closely related to each other, have a serious impact on each other, thereby enhancing the synergistic effect and being an important determinant of the reconstruction of this content. Thus, it is becoming more and more clearly personalized, consistent with the humanitarian nature of the teacher's activities, acquiring the features of a holistic construct from which more and more new meanings are drawn, focused on regional specifics and national traditions and aimed at developing ethnoregional and ethnocultural values for graduates of pedagogical universities. The competence-oriented content of pedagogical education creates maximum opportunities for the development of the subjective position of the future teacher in the profession, the ability to solve professional tasks at a qualitatively new level. Due to the realization of the trend of informatization of the content of pedagogical education, an entry into a new pedagogical reality is carried out. At the same time, the structural fullness of the components of this content changes significantly.

Taking into account the identified trends in the development of the content of pedagogical education in the professional training of future teachers, it will undoubtedly contribute to the mastering by teachers of new ways of project activity, as well as a serious innovative reconstruction not only of the content, but also of the procedural characteristics of the educational process in the higher pedagogical school. 
At the same time, we see the prospects for our further research in the development of didactic principles as leading methodological regulatives that contribute to the successful implementation of each of the identified trends in the development of the content of modern pedagogical education.

\section{References}

1. A. N. Novikov, Methodology of education (Egves, Moscow, 2006)

2. Yu. V. Senko, Humanitarian foundations of teacher education (Publishing center "Academy", Moscow, 2000)

3. M. M. Bakhtin, Aesthetics of verbal creativity (Art, Moscow, 1979)

4. M. Buber, Me and You (High School, Moscow, 1993)

5. Yu. N. Kulyutkina, G. S. Sukhobskaya, (ed.) Modeling pedagogical situations: problems of improving the quality and effectiveness of general pedagogical teacher training (Pedagogy, Moscow, 1981)

6. O. P. Morozova, Economics. Profession. Business, 2, 89-92 (2016)

7. I. A. Kolesnikova, Pedagogical reality: the experience of interparadigmatic reflection (CHILDHOOD-PRESS, St. Petersburg, 2001) 